Devel opment of a new type micro sl ur ry-j et er osi on (MSE) tester for eval uat $i$ on of wear properti es of hard thi $n$ coat ings

\begin{tabular}{|l|l|}
\hline 著者 & $\begin{array}{l}\text { I WAl Yoshi ro, MATSUBARA Tohr u, H RAI Yui chi , } \\
\text { HOGMARK St ur e }\end{array}$ \\
\hline $\begin{array}{l}\text { j our nal or } \\
\text { publ i cat i on ti t l e }\end{array}$ & Lubr i cat i on Sci ence \\
\hline vol une & 21 \\
\hline number & 6 \\
\hline page r ange & 213 226 \\
\hline year & $2009-07$ \\
\hline URL & ht t p: //hdl . handl e. net /10098/2119 \\
\hline
\end{tabular}




\title{
Development of a new type micro slurry-jet erosion (MSE) tester for evaluation of wear properties of hard thin coatings
}

\author{
Yoshiro Iwai(*1), Tohru Matsubara(2), Yuichi Hirai(1) Sture Hogmark(3) \\ (1) Department of Mechanical Engineering, University of Fukui, \\ Bunkyo 3-9-1, Fukui, 910-8507, Japan \\ (2) Macoho Co., Ltd., Isurugi, Nagaoka, Nigata 940-2032, Japan \\ (3) The Angstrom Laboratory, Uppsala University, SE-751 21 Uppsala, Sweden
}

Corresponding author: (*1) University of Fukui, Bunkyo 3-9-1, Fukui, 910-8507, Japan

Tel: +81-776-27-8544, Fax: +81-776-27-8748

E-mail: yiwai@u-fukui.ac.jp

\begin{abstract}
Versatile and reliable techniques for evaluation of hard thin coatings are necessary for the development and tribological assessment of new coatings. We have proposed a new type of micro slurry-jet erosion test (MSE), i.e. a solid particle impact erosion test for swift evaluation of wear properties of hard thin coatings. We are using a new type of MSE test apparatus (pot type tester) that makes it possible to obtain the wear loss per unit mass of erodent, which in this test was alumina particles with $1.2 \mu \mathrm{m}$ in average size. Its performance was evaluated using a $\mathrm{Si}$ wafer plate under various test condition. In addition, the MSE tester was demonstrated by evaluating the wear resistance of TiN on high speed steel substrate. The new MSE test generates highly reproducible results and is very sensitive to the quality of the coatings.
\end{abstract}

KEY WORDS: slurry wear; slurry-jet erosion test; evaluation technique; MSE; coating; TiN

\section{INTRODUCTION}

Several kinds of tests for evaluation of hard thin coatings have been developed for the continuing development and tribological assessment of new coatings. Such tests should distinguish between the individual properties of the coating and substrate materials. Existing tests are evaluating the scratch resistance, nano hardness, and friction and wear resistance [1-3]. However, most of these tests cannot evaluate the properties of coating, substrate and interface independently.

Base on the above backgrounds, we have proposed a micro slurry-jet erosion test (MSE) [4] [5], i.e. a solid particle impact erosion test. We have already shown that our test method is very useful for evaluating the wear depth rate per unit test time, a parameter that can be used to rank test coatings. However, the wear depth per unit weight of erodent is desired to characterize the wear properties of coatings and to facilitate comparison between various types of erosion tests [6-10].

In this study, we set up a new type of MSE test apparatus (pot type tester) by which we can obtain the wear volume per unit mass of erodent. The performance of the tester 
was investigated and the possibility to evaluate hard thin coatings such as TiN was discussed.

\section{EXPERIMENTAL}

\subsection{Test apparatus}

The new MSE apparatus consists of a pot with a stirrer, a nozzle unit and a slurry receiver tray (Figs. 1 and 2). It has an inlet for slurry, i.e. water containing solid particle erodent and an inlet for regulated compressed air. A given amount of slurry is put into the pot. The flowing slurry is mixed and accelerated with regulated compressed air at the nozzle unit, and is then ejected at high velocity. As the surrounding space of test section is covered, all ejected slurry is collected into the receiver tray. The nozzle is made by a super hard alloy, and its cross-section is a square of $3 \times 3 \mathrm{~mm}^{2}$. The maximum volume of slurry in the pot is $1000 \mathrm{~cm}^{3}$.

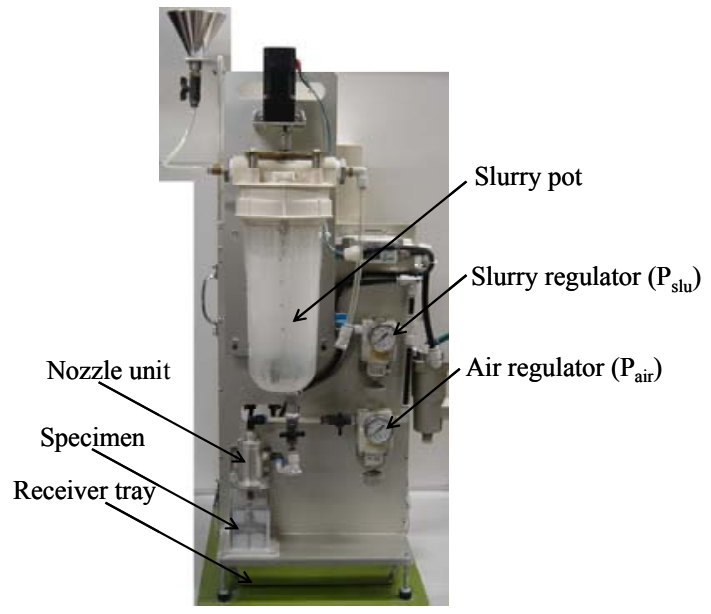

Figure 1 Photograph of the MSE tester

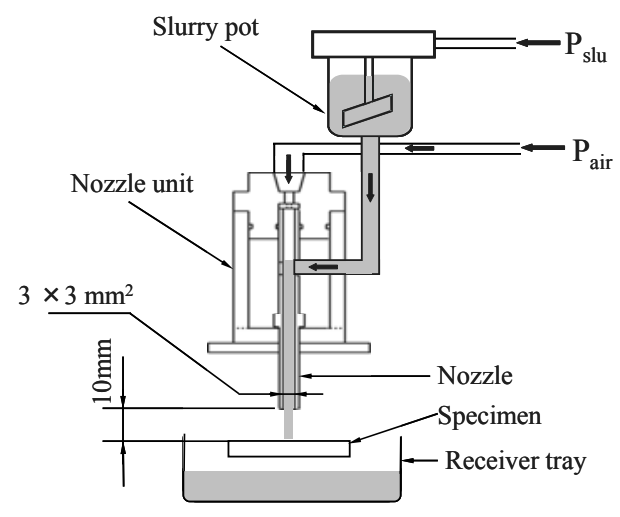

Figure 2 Schematic view of the MSE tester

\subsection{Test procedure}

Angular alumina particles with the size distribution curve shown in Fig. 3 were used as erodent. Their average diameter was $1.2 \mu \mathrm{m}$. The hardness of the alumina particles are estimated to range from $\mathrm{HV}=1800$ to 2000 [11]. Pure water was used as solvent. The slurry concentration (c) used was $\mathrm{c}=1,2$ and 3 mass $\%$, respectively, and the slurry was kept at room temperature. The specimen was mounted $10 \mathrm{~mm}$ away from the nozzle exit in accuracy of $0.2 \mathrm{~mm}$ by measurement with a gauge block. The impingement angle of the slurry-jet relative to the test surface was set to 90 degrees and the slurry jet velocity was regulated by both the compressed air pressure $\left(\mathrm{P}_{\text {air }}\right)$ and slurry pressure $\left(\mathrm{P}_{\text {slu }}\right)$. $\mathrm{P}_{\text {slu }}$ was set to $95 \%$ of $\mathrm{P}_{\text {air. }}$ In each MSE test, a given amount of slurry was impacted on the test surface at a time. This process was repeated depending on the wear resistance and thickness of the tested coatings. 


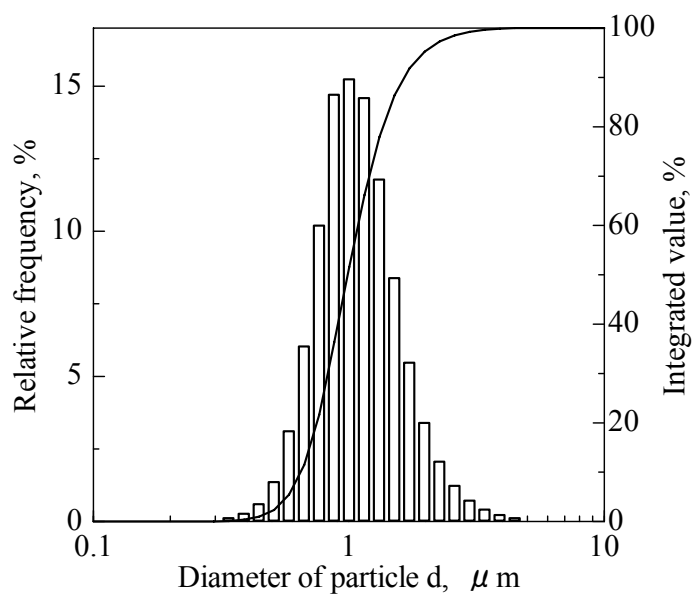

Figure 3 Size distribution of erodent $\left(\mathrm{Al}_{2} \mathrm{O}_{3}\right)$

Since the wear loss of the coatings after test completion was too small to be resolved by weighing, the geometry of the wear scar was measured with a stylus profilemeter at three positions along the centreline of the square wear scar.

\subsection{Test materials}

A single crystal $\mathrm{Si}$ wafer (100) (designated $\mathrm{Si}$ wafer) was used to evaluate the performance of the apparatus. For the evaluation of coatings, the tests were performed on a TiN coating deposited by physical vapour deposition (PVD) using a hollow cathode discharge method. The thickness of the coating was $2 \mu \mathrm{m}$. The coatings were deposited on high speed steel (HSS) plates of $5 \mathrm{~mm}$ in thickness.

The hardness was measured by a nano-indenter, using a Berkovich tip. An electromagnetic actuator was used, and the displacement was measured by a capacitance gauge. The applied load was $50 \mathrm{mN}$. The roughness and nano-hardness of the Si wafer were $\mathrm{Ra}$ $=0.001 \mu \mathrm{m}$ and $13.8 \mathrm{GPa}$, for the as deposited TiN coating $0.1 \mu \mathrm{m}$ and $26.1 \mathrm{GPa}$, respectively. The roughness and hardness of the HSS substrate material were $\mathrm{Ra}=0.004$ $\mu \mathrm{m}$ and $\mathrm{HV}=760$, respectively.

\subsection{Observation of slurry-jet impact by a high-speed video camera}

The velocity of the solid particle erodent and the distribution of the erodent impact at the test surface were observed with a high-speed video camera. The schematic view of the capturing and photographing system is shown in Fig. 4. The camera speed was 250 kfps (kilo frames per second) and the exposure time was $0.25 \mu \mathrm{sec}$ for the slurry-jet observation. A speed of $4 \mathrm{kfps}$ and exposure time of $125 \mu \mathrm{sec}$ were used for the observation of the impact distribution on the glass plate.100 frames were image stored at each recording.

Observation of the slurry-jet was conducted at an area of $5.7 \times 4.7 \mathrm{~mm}^{2}$, which was set $2.8 \mathrm{~mm}$ away from the nozzle exit. Since the individual alumina particle of the 1.2 $\mu \mathrm{m}$ erodent are too small to be recorded with the high-speed camera, glass beads with $73 \mu \mathrm{m}$ in diameter were used instead. A $1 \mathrm{~mm}$ width slit was set directly under the 

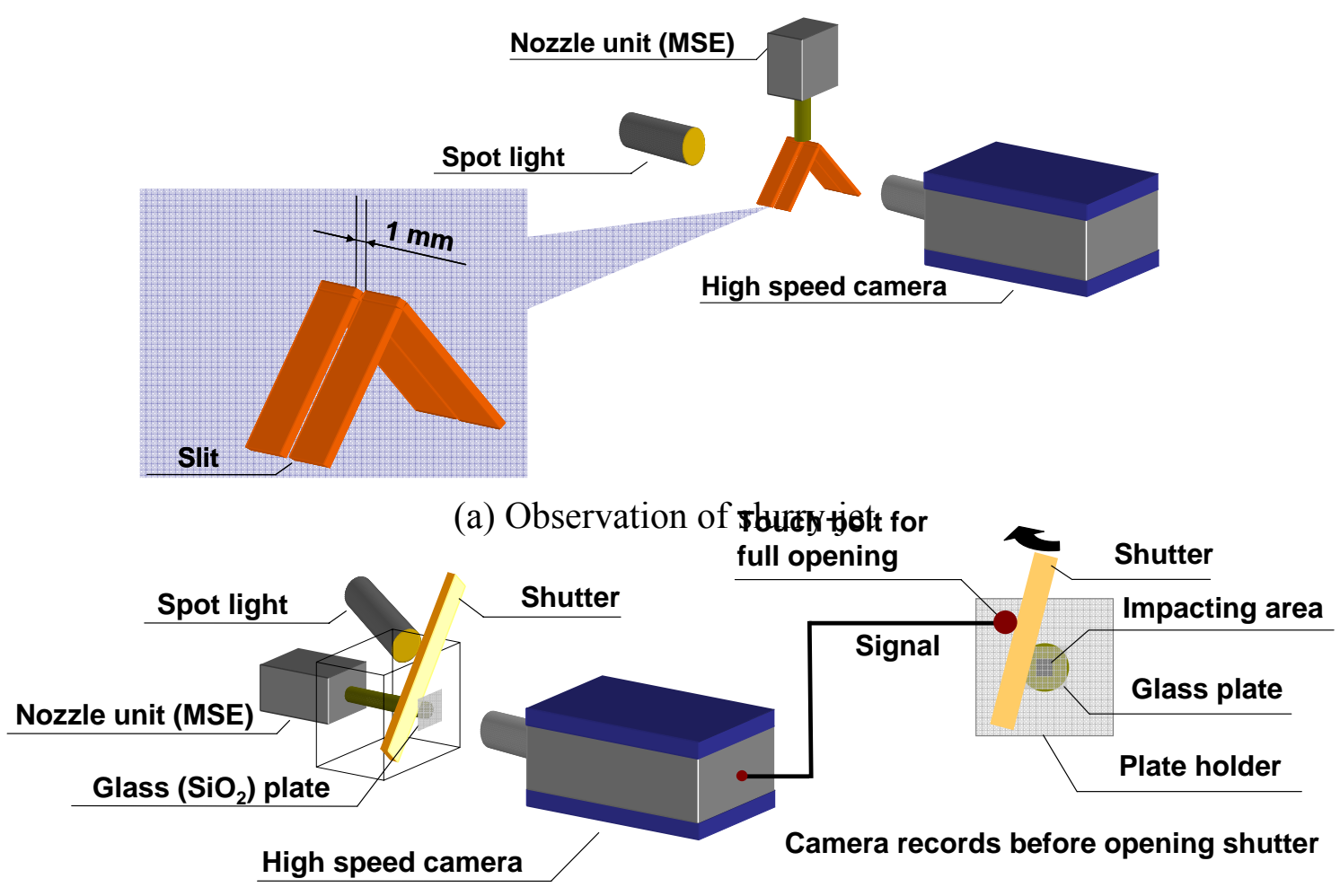

(b) Observation of distribution of impact and detail of the shutter motion

Figure 4 Capturing and photographing system by a high-speed video camera

nozzle exit in order to observe the glass beads erodent in the flowing slurry without the disturbance of flowing water droplets, see Fig.4a.

The distributions of the impacts on the test surface was observed from the back side of a $\mathrm{SiO}_{2}$ glass plate which was set directly under the nozzle instead of the test piece, see Fig. 4b. The surface of the glass plate was thinly covered by a commercial oil-based marker. The glass plate was positioned $10 \mathrm{~mm}$ away from the nozzle exit. A shutter of copper was used. For this experiment, the glass beads with $9 \mu \mathrm{m}$ in diameter were used instead of $1.2 \mu \mathrm{m}$ alumina particles.

\section{RESULTS AND DISCUSSION}

\subsection{Performance of the apparatus}

\subsubsection{Performance of the nozzle}

The rate by which slurry is ejected from the nozzle increases with $\mathrm{P}_{\text {air }}$, see Fig. 5. This means the slurry-jet velocity increases with $\mathrm{P}_{\text {air }}$. The amount of impacting slurry was estimated from the elapsed time after which $1 \mathrm{~kg}$ slurry had been ejected from the nozzle. The tests were repeated 4 times under $\mathrm{P}_{\text {air }}=0.1,0.2,0.3$ and $0.4 \mathrm{MPa}$, respectively. The corresponding relative errors were $0.15,0.69,0.31$ and $0.73 \%$. These values are very small. 


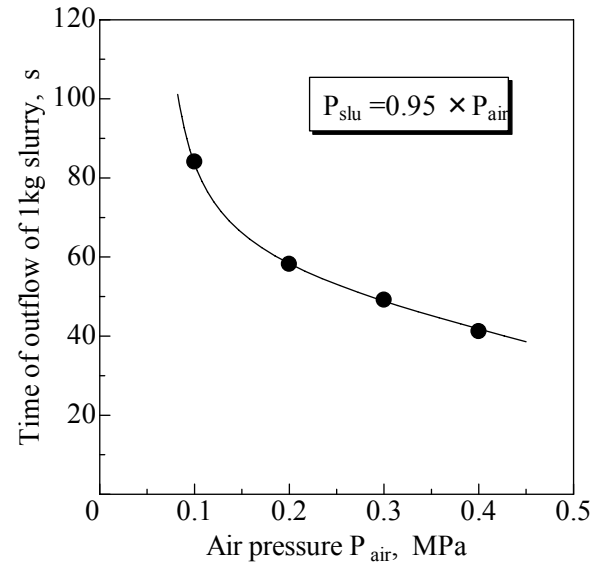

Figure 5 Relation between air pressure $\left(\mathrm{P}_{\text {air }}\right)$ and time of outflow of $1 \mathrm{~kg}$ slurry

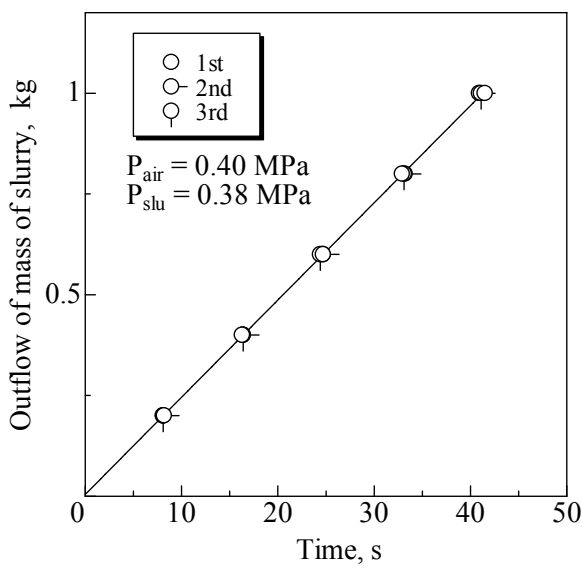

Figure 6 Relation between time and outflow of mass of slurry

The uniformity of the slurry flux was examined by clocking the time for the slurry surface to pass over scale marks, which were put on the sidewall of the pot. Such tests were repeated three times at $\mathrm{P}_{\text {air }}=0.4 \mathrm{MPa}$, and a linear behaviour was demonstrated, except during a few seconds at the beginning and at the end of the slurry flow, see Fig. 6. The pot is finally emptied after a predetermined time. These properties of the apparatus are given by the flow system in which the slurry pressure was applied by compressed air in the slurry pot.

\subsubsection{Impact behaviour of the erodent}

Figure 7 shows an image of the ejected slurry-jet, with a typical mixture of particles and water mist in the main flowing stream. The vectors indicate direction and velocity of observed particles. The flying direction and velocities of the glass bead particles were obtained from series of high-speed photographs.

Although turbulence occurs in the flowing slurry-jet, the particles impact vertically to the test surface. They do not spread since the flowing water stream restrains them. The maximum velocity of the $73 \mu \mathrm{m}$ glass beads was estimated to $145 \mathrm{~m} / \mathrm{s}$. The velocity of the $1.2 \mu \mathrm{m}$ alumina particles is assumed to be even higher since their mass is much smaller.

\subsubsection{Distribution of impact}

Figure 8 shows a series of pictures taken from the backside of the eroded glass plate that initially was covered with marker paint. Areas damaged by the impacting $9 \mu \mathrm{m}$ glass beads are revealed by bright contrast (removal of the marker). Figure $8 \mathrm{a}$ is taken by opening the shutter from the right to left side, and Fig. $8 \mathrm{~b}$ is taken with the shutter opening in the opposite direction. The two series of images look almost the same, and in order to cancel the time lag in opening the shutter, both figures of Figs. 8a and b were 


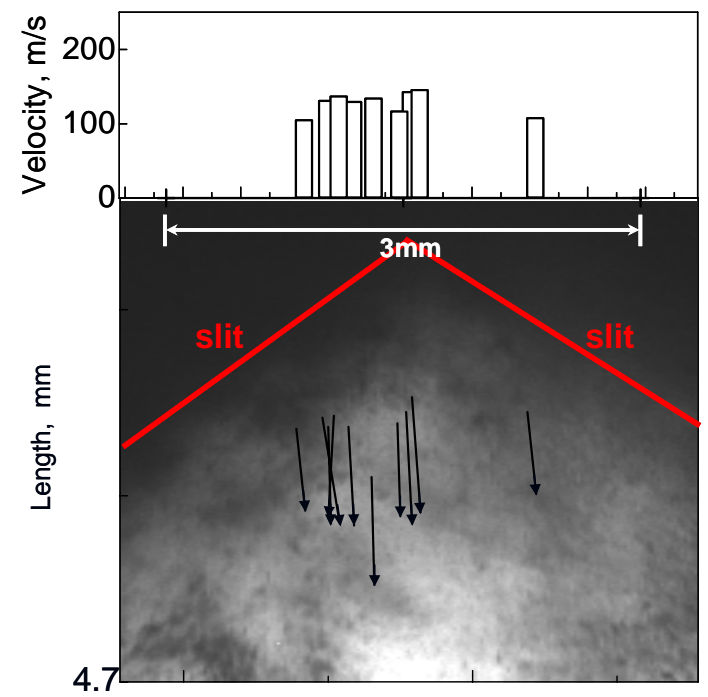

Figure 7 Photograph of the flowing slurry-jet ejected from the nozzle and velocity vectors and velocities of the glass beads $\left(\mathrm{P}_{\mathrm{air}}=0.4 \mathrm{MPa}\right.$, $\mathrm{P}_{\mathrm{sl} l \mathrm{l}}=0.38 \mathrm{MPa}, \mathrm{c}=3$ mass $\%$ )

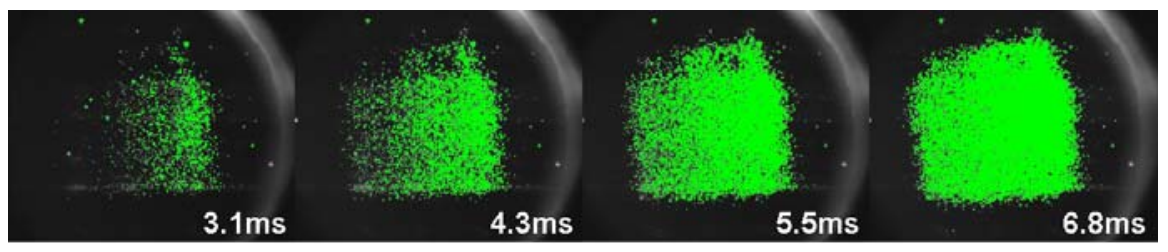

(a) Opening the shutter from the right to left side

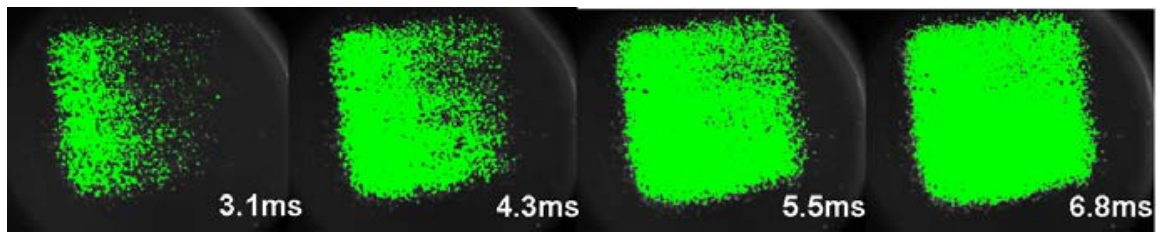

(b) Opening the shutter from the left to right side

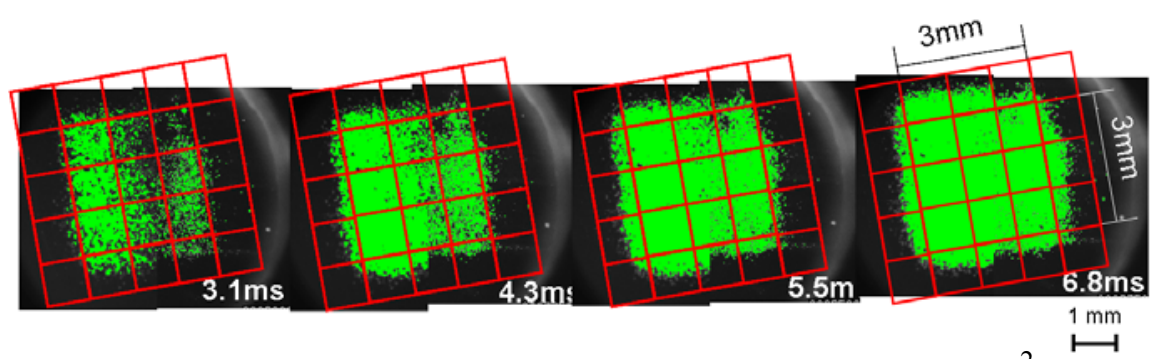

(c) (a) and (b) were superimposed and subdivided into $1 \times 1 \mathrm{~mm}^{2}$ squares

Figure 8 Series of the photographs of the glass plate covered with marker paint taken at each time. ( $3.1 \mathrm{~ms}$ was the time of full opening the shutter.) 
superimposed and subdivided into $1 \times 1 \mathrm{~mm}^{2}$ squares, see Fig. $8 \mathrm{c}$. It is seen that most of the particles ejected from the nozzle impact uniformly within an area corresponding to the nozzle cross-section.

\subsubsection{Wear test}

A wear scar on the Si wafer produced by impacting of 1600 g slurry at $\mathrm{P}_{\text {air }}=0.40 \mathrm{MPa}$ and $\mathrm{c}=3$ mass $\%$ was recorded with a non-contact three-dimensional profilometer, see Fig. 9. The outer shape of the wear scar was almost the same as the nozzle cross-section, i.e., a $3 \times 3 \mathrm{~mm}^{2}$ square. Surface profiles along the centreline (A-A' in Fig. 9) of the wear scar were measured with a stylus profilometer, see Fig. 10. The depth of the profiles is proportional to the amount of slurry impact. The distance between the original and the worn surfaces at the deepest position is designated as the wear depth. The wear depth vs. the amount of impacting slurry shows a true linear behaviour for all conditions tested, see Figs. 11 and 12.

The relative error of Fig. 11 averaged for all measurement values, each based on three parallel tests, was $<3 \%$. This confirms a linear relation between the amount of slurry and wear depth, and that our new apparatus has a good reproducibility and reliability. From these results, the test condition of the MSE tests in the proceeded investigation was set to the highest $\mathrm{P}_{\text {air }}=0.40 \mathrm{MPa}$.

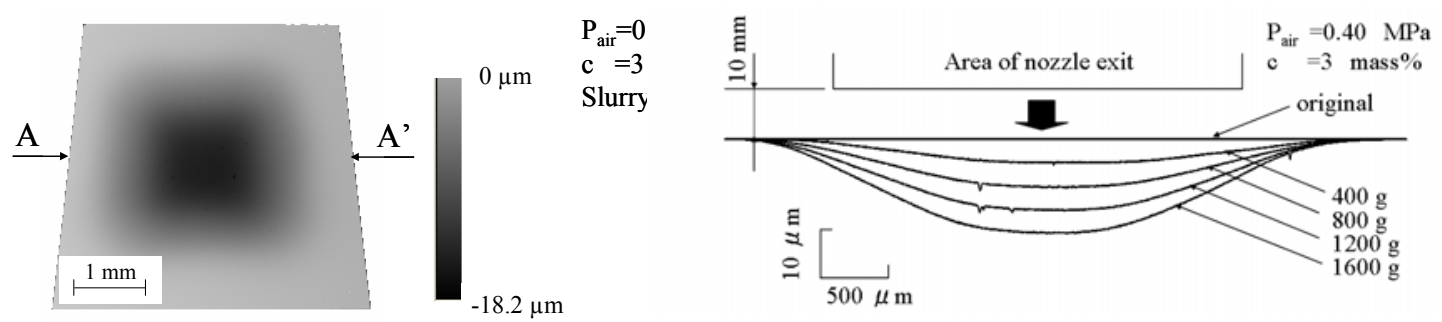

Figure 9 Wear scar on Si wafer

Figure 10 Surface profiles along the centerline of the square wear scar on $\mathrm{Si}$ wafer after different test durations

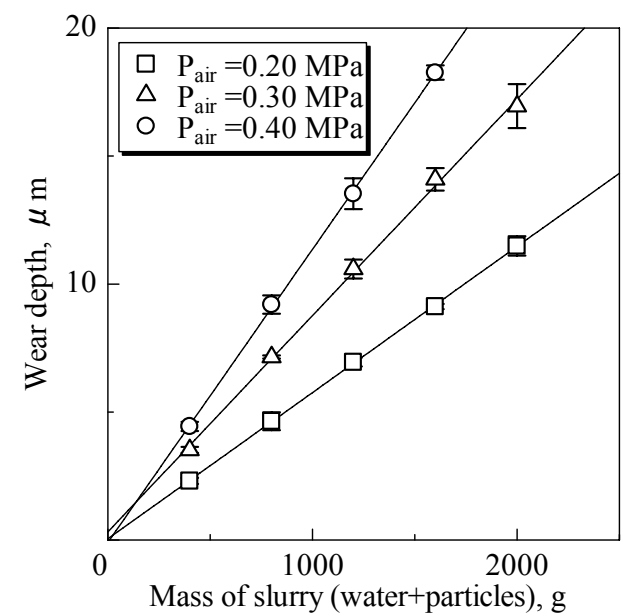

Figure 11 Relation between mass of slurry and wear depth in $\mathrm{Si}$ wafer at various air pressure

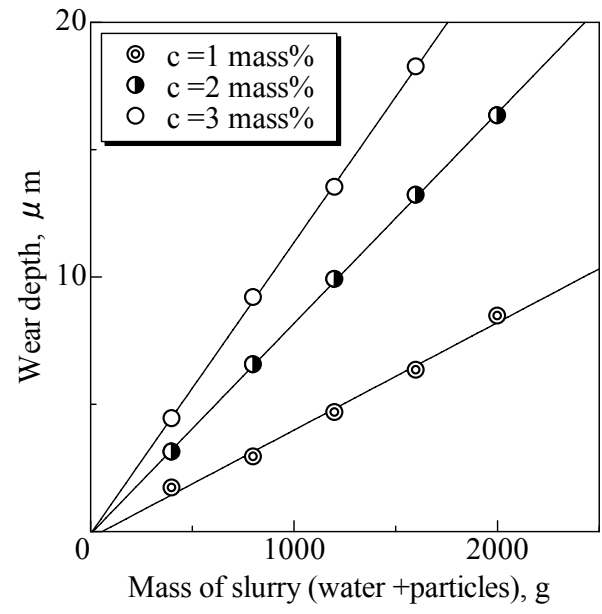

Figure 12 Relation between mass of slurry and wear depth in Si wafer at various slurry concentration 


\subsubsection{Calculation of wear rate}

The total amount of particles that has impacted on the test surface can be calculated by the product of the amount of slurry times its concentration. The wear tests were carried out under $\mathrm{P}_{\mathrm{air}}=0.40 \mathrm{MPa}$ and $\mathrm{c}=1,2$ and 3 mass $\%$ using the Si wafer, see Fig. 12. The wear curves at each slurry concentration became straight lines, and their slopes increased with increasing concentration. Based on the results of Fig. 12, we will try to describe the wear rate vs. the amount of particles. For this calculation, it is necessary to further consider the impact behaviour of the solid particles in the slurry erodent.

Figure 13 shows a wear scar on the Si wafer produced by impacting $200 \mathrm{~g}$ slurry. The shape and size of the wear scar is almost the same as that of the nozzle cross-section (3 $\times 3 \mathrm{~mm}^{2}$ ). With the selected parameters of particle concentration, $\mathrm{P}_{\text {air }}$ and nozzle geometry, the particles are impinging on the test surface with a continuous distribution, and Figs. 13 and 14 represent the distribution of individual impacts. The impacting slurry is obviously free from turbulence even though the nozzle cross-section is a square. A slight increase in roughness of the wear scar with depth was detected already after impingement of $200 \mathrm{~g}$ slurry, see Fig. 14 which represents the wear scar of Fig. 13 subdivided into $0.5 \times 0.5 \mathrm{~mm}^{2}$ squares. A scanning laser microscope was used for the roughness measurements, and surface ten-point height roughness (SzIIS [12]) was utilized. The $\mathrm{Sz}_{\mathrm{IIS}}$-value of the surface before testing was $0.24 \mu \mathrm{m}$. The roughness increase is probably due to statistical variations in particle size, impact site, velocity distribution, and distribution of impact angle for the individual particles. The same phenomenon of increasing roughness is well known from e.g. macroscopic sand blasting and atomic level ion beam milling. When comparing the square wear scar to the circular wear scar generated by a nozzle with a circular cross-section, a larger part of the central region is uniformly eroded in the square wear scar. This is beneficial to the wear depth assessment, and motivates the choice of the square shaped nozzle.

Based on the above consideration, the mass of impacting slurry is converted into the mass of particles per unit area by the following equation.

Q (kg) : mass of slurry

c $(\operatorname{mass} \%)$ : slurry concentration

$\mathrm{A}_{0}\left(\mathrm{~mm}^{2}\right) \quad$ : slurry impacted area (nozzle cross-section $3 \times 3 \mathrm{~mm}^{2}$ )

$\mathrm{W}\left(\mathrm{g} / \mathrm{mm}^{2}\right)$ : mass of particles per unit area.

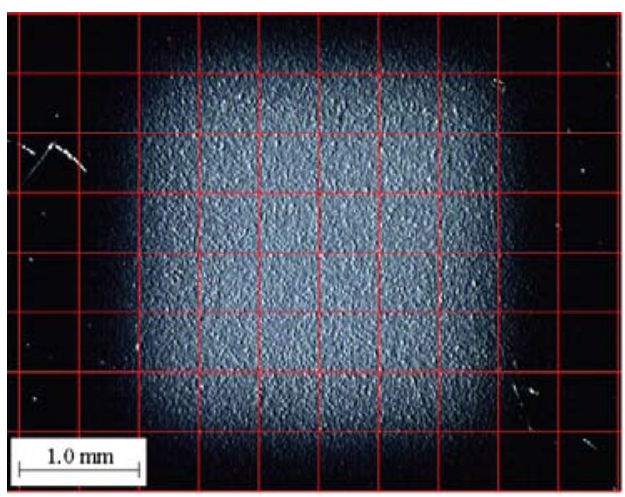

Figure 13 Wear scar on Si wafer after Figure 14 Distribution of roughness SzIIS impact of $200 \mathrm{~g}$ slurry of 3 $\operatorname{mass} \%$

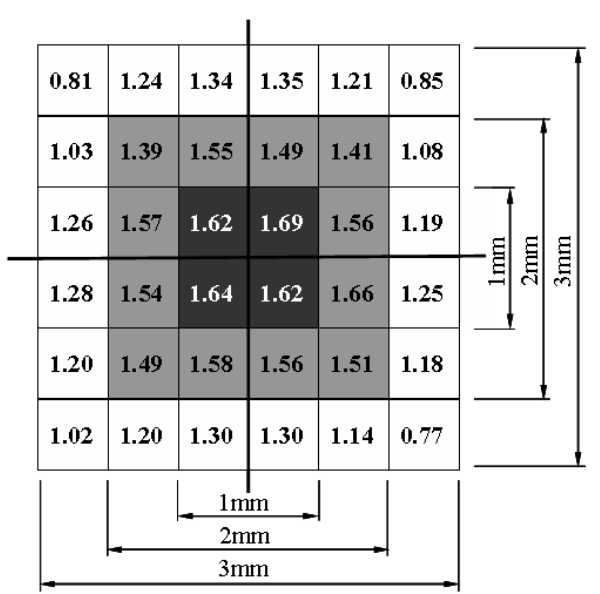

$(\mu \mathrm{m})$ in the wear scar of Fig. 13 


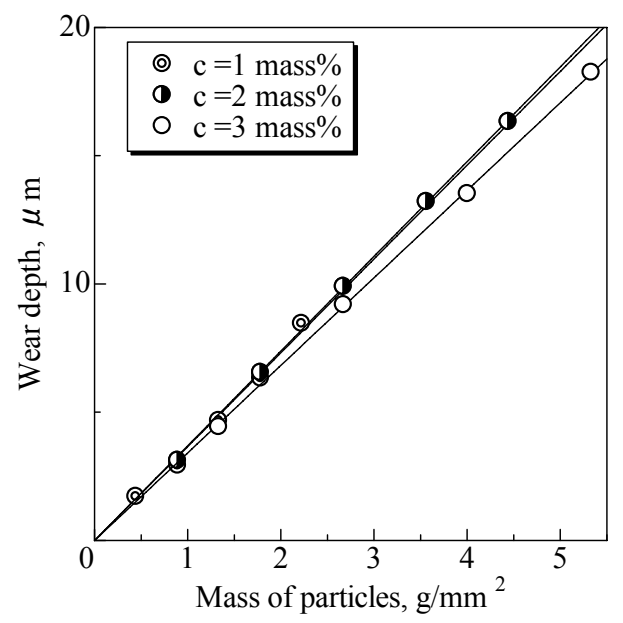

Figure 15 Relation between mass of particle and wear depth in Si wafer at various slurry concentration

Therefore,

$\mathrm{W}=\mathrm{Q} \times \mathrm{c} \times 1 / \mathrm{A}_{0}$

In the tests, $A_{0}$ represents the nozzle cross-section of $3 \times 3 \mathrm{~mm}^{2}$, the unit area is the central area of $1 \times 1 \mathrm{~mm}^{2}$ of the wear scar where the wear depths are measured. Thus, equation (1) becomes

$\mathrm{W}=\mathrm{Q} \times \mathrm{c} \times 1 / 9$

The wear depth is measured in the central area of $1 \times 1 \mathrm{~mm}^{2}$ of the wear scar.

Using equation (2), Fig. 12 can be transformed to give the wear depth vs. particle mass, see Fig. 15. The wear rates of the different slurry concentrations are now confined to a single straight lines with slopes of $3.4 \sim 3.7 \mu \mathrm{m} /\left(\mathrm{g} / \mathrm{mm}^{2}\right)$, which is the wear rate per unit mass of particles of erodent impacting on the unit area. The three different concentrations of erosive particles generate slightly different normalized wear rates, with the highest wear rate for the lowest concentration. Consequently, there is a slight interaction between the eroding particles, and this interaction increases with the concentration, i. e. the wear becomes smaller with increasing probability of particle collision.

In addition, if the recorded wear depth is multiplied by unit area, the wear rate can be described by the wear volume. In this case, the average wear rate for the three concentrations is $3.6 \times 10^{-3} \mathrm{~mm}^{3} / \mathrm{g}$.

\subsection{Wear test of coatings}

The wear scar profile of the TiN coating resembles that from the Si wafer, cp. Figs. 10 and 16. The central $1 \mathrm{~mm}^{2}$ area of the TiN wear scar is almost uniformly deep, and the coating was penetrated after impacting about $12 \mathrm{~kg}$ slurry. Once the coating is penetrated, the wear rate increases dramatically, indicating a much lower wear resistance of the HSS substrate material, see Fig. 17. It is seen in this figure that each slurry concentration gives a very linear wear rate. Again using equation (2) for transformation gives the wear rate in $\left[\mu \mathrm{m} /\left(\mathrm{g} / \mathrm{mm}^{2}\right)\right]$, see Fig. 18 where the slight particle interaction is again revealed by the presence of three separate curves for TiN. The slopes of the TiN coating and substrate wear curves are $0.064,0.055,0.050 \mu \mathrm{m} /(\mathrm{g}$ 
$\left./ \mathrm{mm}^{2}\right)$ and $0.96,1.03,0.99 \mu \mathrm{m} /\left(\mathrm{g} / \mathrm{mm}^{2}\right)$ for the slurry concentrations $1,2,3 \mathrm{mass} \%$, respectively.

The cross-over between the curves representing the TiN coating and those representing the HSS substrate can be used to read the coating thickness (about $2.0 \mu \mathrm{m}$ ) and also the mass of particles per unit area needed for coating penetration $(31,35$ and $38 \mathrm{~g} / \mathrm{mm}^{2}$ for the concentrations 1,2 and 3 mass $\%$, respectively). Note also that the 3 mass\% curve representing the uncoated substrate is parallel to the 3 mass\% curve representing the HSS substrate under the TiN coating.

The conclusion is that our test is able to determine the wear properties of thin hard coatings independently from the properties of the substrate. For $\mathrm{c}=3 \mathrm{mass} \%$, the wear rate of TiN coating was $5.0 \times 10^{-5} \mathrm{~mm}^{3} / \mathrm{g}$.

For comparison, the wear rate of a TiN coating obtained by the ASTM standard G7602 erosion test (a particle velocity of 60 or $84 \mathrm{~m} / \mathrm{s}$, angular alumina $\left(\mathrm{Al}_{2} \mathrm{O}_{3}\right)$ powders with an average size of $50 \mu \mathrm{m}$, impingement angle of $90^{\circ}$ ) was reported to be $4.5 \times 10^{-3}$ $\mathrm{mm}^{3} / \mathrm{g}$ [9]. The relative error for repeated tests seems to properly monitor the depth scale accuracy as well as the wear rate when comparing the sensitivity of our MSE test with the ASME test. Unfortunately, the relative error of the above ASTM test was not reported in the literature. Severity of erosion damage generally depends on the erodent size. Our MSE test gives a very mild damage because the erodent size was about 1/40 of

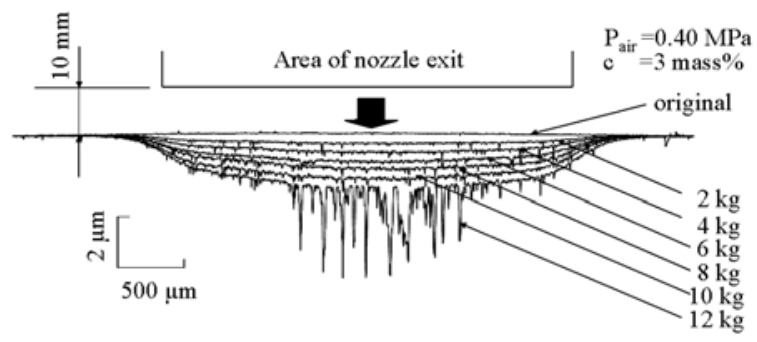

Figure 16 Surface profiles along the center-line of the square wear scar of the TiN coating after different test durations

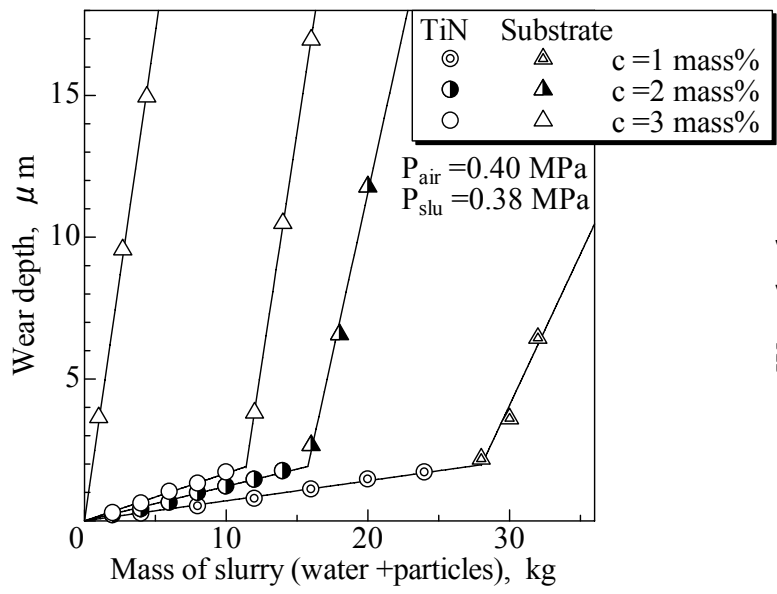

Figure 17 Relation between mass of slurry and wear depth at various air concentration for TiN on HSS

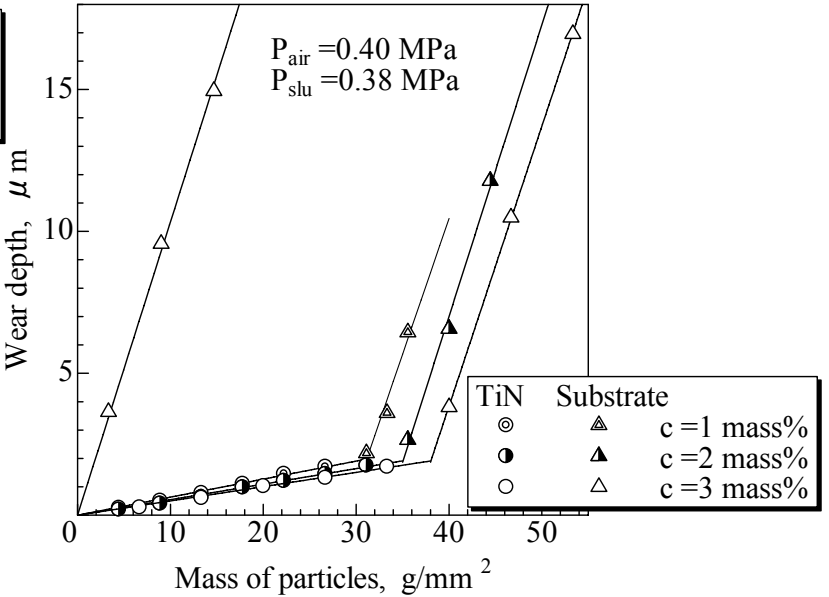

Figure 18 Relation between mass of particles and wear depth in TiN on HSS 
that of literature. Our results indicate that the sensitivity of the MSE test is about 100 times better. This means that the MSE test is much more suitable for evaluation of thin multi-layered coatings, thin coatings with gradients, coating/substrate interfaces, etc. than the ASTM test. It would also be a very good test for any other type of surface layers such as oxide scales, hard lacquers, tribo films, etc.

\section{CONCLUSIONS}

1. The properties of a new pot type MSE apparatus were examined using a single crystal Si wafer specimen as reference, and a PVD TiN coating for demonstration.

2. The slurry particles impact uniformly on an area which corresponds to the shape of the nozzle, i.e. a square of $3 \times 3 \mathrm{~mm}^{2}$.

3. The wear rate of the coatings per unit mass of particles in the slurry was $5.0 \times 10^{-5} \mathrm{~mm}^{3} / \mathrm{g}$ for TiN coating.

4. The new MSE test is able to assess the wear properties of thin hard coatings independently from the properties of the substrate.

5. The high sensitivity of the MSE test also makes it suitable for evaluation of multilayered coatings and of the interface between coating and substrate.

6. A test with the above properties should also be very good for evaluating other types of thin surface films such as oxide scales, hard lacquers, tribo films, etc.

\section{ACKNOWLEDGEMENTS}

This study was supported by a Grant-in-Aid administered by the Japan Society for the Promotion of Science (JSPS) (No. 18360076). The authors are grateful to JSPS.

\section{REFERENCES}

[1] Holmberg K, Matthews A. Tribology Series 28: Coating Tribology. Elsevier: Amsterdam, 1994.

[2] Hogmark S, Jacobson S, Larssson M, Wiklund U, in: Bhushan B, (Ed.). Modern Tribology Handbook II: Mechanical and tribological requirements and evaluation of coating composites. CRC Press, 2001; 931-963.

[3] The Japan Society of Mechanical Engineers (Ed.). Standard Method for Evaluating the Defects in the Coatings Made by Dry Processing. The Japan Society of Mechanical Engineers, 1996; 1-5.

[4] Iwai Y, Honda T, Yamada Y, Matsubara T, Larsson M, Hogmark S. Evaluation of wear resistance of thin hard coatings by a new solid particle impact test. Wear 2001; 251: 861-867.

[5] Iwai Y, Miyajima T, Honda T, Matsubara T, Kanda K, Hogmark S. Evaluation of erosive wear resistance of TiN coatings by a slurry jet impact test. Wear 2006; 261: 112-118.

[6] Hutchings IM. Abrasive and erosive wear tests for thin coatings: a unified approach. Tribol. Int. 1998; 31 (1-3): 5-15.

[7] Bromark M, Larsson M, Hedenqvist P, Hogmark S. Determination of coating erosion resistance using the mass-loss technique. Proceedings of the 6th Nordic 
Symposium on Tribology 1994: 207-214.

[8] Gant AJ, Gee MG. Wear of tungsten carbide-cobalt hardmetals and hot isostatically pressed high speed steels under dry abrasive conditions. Wear 2001; 251: 908-915.

[9] Yang Q, Seo DY, Zhao LR, Zeng XT. Erosion resistance performance of magnetron sputtering deposited TiAlN coatings. Surface \& Coatings Technology 2004; 188-189: 168-173.

[10] Kenneth BG. Evaluating the abrasion resistance of coatings with abrasive finishing tape. Surface \& Coatings Technology 2004; 188-189: 539-543.

[11] Hutchings IM. Tribology: Friction and Wear of Engineering Materials. Edward Arnold: London, 1992; 137.

[12] Hara S, Yanagi K, Matsuo S, Yamada R. Surface topography measurement using confocal scanning laser microscope and functional digital filtering. Journal of the Japan Society for Precision Engineering 1998; 64, 5: 710-714. 